\title{
Understanding socio-economic inequalities in food choice behaviour: can Maslow's pyramid help?
}

\author{
Frank J. van Lenthe*, Tessa Jansen and Carlijn B. M. Kamphuis \\ Department of Public Health, Erasmus MC, Rotterdam, The Netherlands \\ (Submitted 15 May 2014 - Final revision received 24 November 2014 - Accepted 15 January 2015 - First published online 18 March 2015)
}

\section{Abstract}

Socio-economic groups differ in their material, living, working and social circumstances, which may result in different priorities about their daily-life needs, including the priority to make healthy food choices. Following Maslow's hierarchy of human needs, we hypothesised that socio-economic inequalities in healthy food choices can be explained by differences in the levels of need fulfilment. Postal survey data collected in 2011 (67.2\% response) from 2903 participants aged 20-75 years in the Dutch GLOBE (Gezondheid en Levens Omstandigheden Bevolking Eindhoven en omstreken) study were analysed. Maslow's hierarchy of human needs (measured with the Basic Need Satisfaction Inventory) was added to age- and sex-adjusted linear regression models that linked education and net household income levels to healthy food choices (measured by a FFQ). Most participants (38.6\%) were in the self-actualisation layer of the pyramid. This proportion was highest among the highest education group (47.6\%). Being in a higher level of the hierarchy was associated with a higher consumption of fruits and vegetables as well as more healthy than unhealthy bread, snack and dairy consumption. Educational inequalities in fruit and vegetable intake $(B=-1 \cdot 79,95 \% \mathrm{CI}-2 \cdot 31,-1 \cdot 28$ in the lowest education group) were most reduced after the hierarchy of needs score was included $(B=-1.57,95 \% \mathrm{CI}-2 \cdot 09,-1 \cdot 05)$. Inequalities in other healthy food choices hardly changed after the hierarchy of needs score was included. People who are satisfied with higher-level needs make healthier food choices. Studies aimed at understanding socio-economic inequalities in food choice behaviour need to take differences in the priority given to daily-life needs by different socioeconomic groups into account, but Maslow's pyramid offers little help.

Key words: Food choice: Socio-economic inequalities: Maslow's hierarchy of needs

The healthy food choice behaviour of adults is inversely related to socio-economic position $(\mathrm{SEP})^{(1,2)}$. Those with lower levels of education or income purchase a greater proportion of less healthy foods and beverages ${ }^{(3)}$, and they consume fewer healthy food products, such as fruits and vegetables ${ }^{(2)}$. Reducing these inequalities through the promotion of healthy food choices in lower socio-economic groups is a major challenge and requires knowledge about the underlying mechanisms on which such interventions and policies should be based.

Why do people in lower socio-economic groups make more unhealthy food choices? One potentially important reason is that healthy food may be, or is perceived to be, more expensive and therefore less affordable for lower socio-economic groups. Furthermore, purchasing healthy food requires knowledge about the nutrition content of food products and the relationship between nutrients and diseases; such knowledge increases with increasing levels of education ${ }^{(4,5)}$. In addition, intra-personal characteristics (such as attitudes towards healthy eating) are less prevalent among lower socio-economic groups and contribute to socio-economic inequalities in food purchasing behaviour ${ }^{(6)}$. Individuals in lower socio-economic groups may also have less access to shops that sell healthy food, although evidence suggests that this explanation mainly applies in the US context ${ }^{(7)}$.

A limited budget, a lack of knowledge, a poor attitude and reduced access to healthy shops all directly limit the purchase of healthy food. Interventions that target these factors implicitly assume there will be an increase in healthy food purchasing behaviour once these constraints have been eliminated. Although there is some evidence to support this assumption ${ }^{(8)}$, this approach largely ignores the fact that socio-economic groups also differ in many factors other than health. The priority given to healthy eating may also depend on, or compete with, challenges in other domains of life. When confronted with problems related to decent housing, residential safety or social relationships, for example, improving the quality of food consumption may simply not be given the highest priority. The fact that challenges in other domains of life receive more priority than the challenge to eat healthily could also be the reason for the low participation of lower socio-economic groups in intervention studies aimed at improving food-related knowledge and attitudes ${ }^{(9)}$. Consequently, one hypothesis

Abbreviation: SEP, socio-economic position.

*Corresponding author: Dr F. J. v. Lenthe, email f.vanlenthe@erasmusmc.nl 
is that purchasing and consuming healthy food is perhaps not among the main priorities of individuals in lower socioeconomic groups because of their higher exposure to challenges in other domains of life.

How people prioritise some needs over others is well described in Maslow's 'hierarchy of needs ${ }^{, 10)}$. According to Maslow's theory, individuals strive to fulfil their individual potential. To do so, basic physiologic needs are prioritised, and only when these are fulfilled will people strive to fulfil higher needs. Once basic needs such as sufficient food and shelter are met, needs in the second layer, which involves safety issues (including financial safety and health care protection), become relevant. Needs in the third layer deal with 'belongingness', that is, the need to be part of a family, community or society. The fourth layer includes needs related to self-esteem, prestige and status. If all of these lower-level needs are partially or fully satisfied, people will then strive for self-actualisation. Self-actualisation is defined as a 'desire for self-fulfilment ${ }^{(10)}$ and can take different forms, such as being creative, altruistic or athletic, for different people.

Maslow's hierarchy offers an interesting framework for understanding socio-economic inequalities in food choice behaviour if two assumptions are met. First, individuals with higher levels of education or income satisfy more basic needs and therefore end up higher in the hierarchy. Second, an interest in making healthy food choices instead of solely satisfying the need to consume sufficient energy becomes larger at higher levels of the hierarchy and becomes prioritised only once other needs are satisfied. There is ample evidence for the first assumption: lower socio-economic groups more often struggle to satisfy lower-level needs. For example, they more often report housing problems, problems meeting ends financially, problems with job security, safety issues and lower social cohesion ${ }^{(11-13)}$. Material factors, including problems meeting ends financially, contribute significantly to socio-economic inequalities in health ${ }^{(14)}$. The second condition, however, seems to be more complicated. Why would making healthy food choices become more relevant at higher levels of the hierarchy only once lower-level needs are met? We argue that this can be best understood in the context of the current 'obesogenic' environments in which food choices have to be made and the abundance of high-energy food in those environments. Over the past few decades, the proportion of fast-food outlets substantially increased $^{(15)}$, and snacks are now almost unavoidable in supermarkets ${ }^{(16)}$. In such environments, the basic need of sufficient energy intake is easily satisfied. When surrounded by an abundance of unhealthy alternatives, however, making healthy food choices can increasingly be seen as a need to reach to self-fulfilment. As such, it becomes a need that will not be satisfied until all lower-level needs are met; it will just not be a priority.

No previous study has investigated whether Maslow's pyramid of needs is useful as a framework for understanding socio-economic inequalities in healthy food choice behaviour. From the Dutch GLOBE (Gezondheid en Levens Omstandigheden Bevolking Eindhoven en omstreken) cohort study, which is aimed at understanding socio-economic inequalities in health and health behaviour ${ }^{(17)}$, we collected data on food choices; we then measured Maslow's needs with the Basic Need Satisfaction Inventory, a questionnaire specifically developed for this purpose ${ }^{(18)}$. This allowed us to test the following hypotheses:

1. High socio-economic groups more often reach a higher level of needs fulfilment than low socio-economic groups do.

2. The more needs that are fulfilled, the more likely people are to make healthy food choices.

3. Socio-economic inequalities in healthy food choices are explained by differences in the level of needs fulfilment.

\section{Methods \\ Population}

Data for the present study come from the most recent wave of data collection in the prospective GLOBE study in 2011. The GLOBE study aims to make a quantitative assessment of the contribution of the mechanisms and factors that underlie socio-economic inequalities in health and health behaviours. The design of the study as well as an overview of its main findings have been described elsewhere ${ }^{(17,19)}$. More detailed information about the rationale for and variables included in the 2011 survey has also been described elsewhere $^{(20)}$.

In 2004, a sample representative of the source population of residents in Eindhoven and its surroundings who were aged 25-74 years and were born in the Netherlands was created ( $n$ 4785). Because people in the sample died, emigrated and were lost to follow-up between 2004 and 2011, a sample of 4437 people were invited to complete the postal survey. The response was $67 \cdot 2 \%$, so data became available for 2983 people. In most cases, missing values for sex ( $n$ 21), age ( $n$ 24) and education level ( $n$ 172) could be replaced by information from the 2004 questionnaire. For some respondents, this information could not be traced in previous waves. Other respondents with missing values for sex, age, and education were excluded ( $n$ 30). Additionally, respondents with missing values for the variables that were needed for the construction of the layers in the hierarchy of needs (described later in the paper) were excluded ( $n$ 50). As a result, the analytic sample comprised 2903 respondents.

\section{Food choice behaviour}

Self-reported information on the number of days per week that respondents consumed specific food items was obtained from a FFQ. The FFQ was based on previous questionnaires ${ }^{(21-23)}$ and asked for the number of days per week that specific food items were consumed (never, $<1 \mathrm{~d} /$ week, $1-2 \mathrm{~d} /$ week, 3-4d/week, 5-6d/week or every day). There were seven food product groups: fruits and vegetables, meat products, bread products, beverages, dairy products, snacks and ready meals. For fruit and vegetable consumption, a sum score was computed by summing the frequency (days per 
week) with which the subject ate fruits, raw vegetables and cooked vegetables. For the other six food groups, outcomes were computed by constructing food group scores for the healthy products within a food group and the unhealthy products within the same food group and then subtracting the latter from the former. For example, within the food group of meat products, the frequency of 'unhealthy' meat products consumption was subtracted from the frequency of healthy meat products consumption. Thus, positive scores indicated more healthy than unhealthy consumption. We subtracted the unhealthy from the healthy outcomes, because doing so is the best way to measure the present hypothesis that being higher in the pyramid results in more healthy than unhealthy food choices; solely focusing on the healthy choices would mask the unhealthy choices. Appendix 1 provides a detailed list of all of the food items used in each food group.

\section{Hierarchy of needs}

Maslow's theory has been operationalised in a twentyseven-item questionnaire called the Basic Need Satisfaction Inventory ${ }^{(18)}$. For each item, participants were asked to rate how they felt about aspects of their lives on a scale of 1 ('terrible') to 7 ('delighted'). Each item is intended to reflect one of Maslow's five basic need categories and hence belongs to one of five conceptual subscales. These range from the lowest layer, or physiological needs ( $\alpha=0.759)$, to safety and security needs ( $\alpha=0.824$ ) to love and belongingness needs ( $\alpha=0.826$ ) to (self-)esteem needs ( $\alpha=0 \cdot 819)$ to the highest layer, or selfactualisation needs ( $\alpha=0.865$ ). Appendix 2 presents the items used for the construction of each of the five layers of the pyramid. For each layer, the mean value of scores for the items was calculated. Data from subjects responding to fewer than $75 \%$ of the items in any layer of the pyramid were considered missing ${ }^{(23)}$. The mean scores for each layer were dichotomised in high/low scores, where 0 indicated 'need not fulfilled' and 1 indicated 'need fulfilled'. This was based on a cut-off point of $\geq 5$ for a high score (Likert-scale answer categories of 'mostly satisfied', 'pleased' and 'delighted'), and $<5$ for a low score (Likert-scale answer categories of 'terrible', 'unhappy', 'mostly dissatisfied' and 'mixed (about equally satisfied and dissatisfied)'). These dichotomous variables allowed us to distinguish satisfaction with a need (mean score $\geq 5$ ) from dissatisfaction with a need (mean score $<5$ ). An important element of Maslow's pyramidal hierarchy of needs is that people can only reach a higher level in the pyramid if lower-level needs are partially or fully satisfied. Thus, people categorised in the layer of safety and security are satisfied with basic physiological needs (the lowest level) but not with love and belongingness needs (higher levels above the layer of safety and security). According to Maslow's theory, people who are satisfied with higher-levels needs but not with lower-level needs cannot be classified in any layer of the pyramid. We used the dichotomous classifications of 'fulfilled' and 'unfulfilled' for each need to construct the pyramid score, which ranged from 0 (dissatisfied with all needs, including physiological needs) to 5 (satisfied with all needs, including self-actualisation needs).

\section{Socio-economic position}

SEP was measured by a respondent's highest attained education level and current income level. A total of eight detailed categories of education were collapsed into four main categories: (1) low SEP (no education or primary education); (2) mid-low SEP (lower vocational or intermediate general education); (3) mid-high SEP (intermediate vocational or higher general education; or (4) high SEP (higher professional education or university). Information about household income was obtained by asking participants to report their net monthly household income from six broad categories (0-1200 euro, 1200-1800 euro, 1800-2600 euro, 2600-4000, 4000 and more or 'I don't know/I don't want to provide this information').

\section{Confounders}

Age (in years), sex and marital status (married or single/ divorced/widowed) were considered confounders of the association between the basic needs and food choice behaviour, and they were therefore controlled for in all analyses. Because adjustment for marital status did not alter the results significantly, final analyses were only adjusted for age and sex.

\section{Statistical analyses}

To investigate whether socio-economic groups differed in their levels of needs fulfilment, we first cross-tabulated the pyramid score by level of education. Subsequently, age- and sexadjusted linear regression analysis was used to investigate the association between education (and income) and healthy food choices. To answer the question of whether the pyramid score contributed to socio-economic inequalities in healthy food choices, we added the pyramid score to models that linked education (and income) with food choice behavioural outcomes. Following the mediation analysis approach of Baron \& Kenny ${ }^{(24)}$ allowed us to assess the association between the pyramid score and healthy food choices after adjusting for age, sex and education as well as the attenuation of the regression coefficients for education. All analyses were conducted in SPSS version 20.0 (IBM SPSS).

\section{Results}

The present sample included more women than men (Table 1). More than $40 \%$ of the population was aged 60 years or older. People below the age of 60 years were generally more highly educated, and people older than 60 years were more often lower educated. There was a clear educational gradient by level of income; people with higher incomes often had higher levels of education.

\section{Classification of study population according to Maslow's hierarchy of needs}

In the present study population, $13 \%$ indicated that none of their needs were fulfilled (Table 1). The proportion of people who were dissatisfied with all of their needs was highest among 
Table 1. Sample characteristics of analytic sample of participants in the 2011 GLOBE (Gezondheid en Levens Omstandigheden Bevolking Eindhoven en omstreken) study in the Netherlands

(Number of participants and percentages)

\begin{tabular}{|c|c|c|c|c|c|c|c|}
\hline \multirow[b]{2}{*}{ Total sample ( $n$ 2903) } & \multirow[b]{2}{*}{$n \dagger$} & \multirow[b]{2}{*}{$\%^{*}$} & \multicolumn{4}{|c|}{ Education level (\%)* } & \multirow[b]{2}{*}{$P$} \\
\hline & & & 1 (low) & 2 & 3 & 4 (high) & \\
\hline Sex & & & & & & & $<0.0001$ \\
\hline Women & 1607 & $56 \cdot 6$ & $58 \cdot 2$ & $66 \cdot 7$ & $55 \cdot 6$ & $48 \cdot 2$ & \\
\hline Men & 1286 & 43.4 & $41 \cdot 8$ & $33 \cdot 3$ & 44.4 & $51 \cdot 8$ & \\
\hline Age (15-year classes) & & & & & & & $<0.0001$ \\
\hline $31-44$ years & 502 & 23.0 & 9 & $7 \cdot 6$ & $29 \cdot 8$ & $33 \cdot 7$ & \\
\hline $45-59$ years & 758 & $33 \cdot 6$ & $15 \cdot 8$ & $29 \cdot 6$ & $39 \cdot 8$ & $35 \cdot 3$ & \\
\hline $60-74$ years & 1188 & $34 \cdot 7$ & $46 \cdot 3$ & 51.4 & $25 \cdot 1$ & $25 \cdot 3$ & \\
\hline$\geq 75$ years & 445 & $8 \cdot 8$ & $28 \cdot 8$ & 11.3 & $5 \cdot 3$ & $5 \cdot 8$ & \\
\hline \multicolumn{8}{|l|}{ Education level } \\
\hline 1 (low) & 246 & $6 \cdot 1$ & - & - & - & - & \\
\hline 2 & 1013 & $31 \cdot 2$ & - & - & - & - & \\
\hline 3 & 675 & $26 \cdot 8$ & - & - & - & - & \\
\hline 4 (high) & 959 & 35.9 & - & - & - & - & \\
\hline Income & & & & & & & $<0.0001$ \\
\hline 1 (low) & 248 & 7.9 & 29.8 & $12 \cdot 6$ & 5.4 & $2 \cdot 1$ & \\
\hline 2 & 492 & $15 \cdot 3$ & $27 \cdot 5$ & $25 \cdot 3$ & 14.5 & $5 \cdot 1$ & \\
\hline 3 & 692 & $21 \cdot 3$ & $16 \cdot 3$ & $25 \cdot 2$ & $24 \cdot 3$ & $16 \cdot 6$ & \\
\hline 4 & 736 & $28 \cdot 8$ & 3.4 & $16 \cdot 9$ & $35 \cdot 1$ & $38 \cdot 6$ & \\
\hline 5 (high) & 333 & $13 \cdot 4$ & 0 & $3 \cdot 2$ & 9.5 & $27 \cdot 6$ & \\
\hline Missing & 392 & $13 \cdot 3$ & 23 & $16 \cdot 9$ & $11 \cdot 2$ & 10 & \\
\hline Level in BNSI pyramid & & & & & & & $<0.0001$ \\
\hline 0 (not satisfied) & 378 & $13 \cdot 0$ & 23.9 & $16 \cdot 4$ & 12.5 & 8.6 & \\
\hline 1 (physiological) & 298 & $9 \cdot 7$ & $9 \cdot 6$ & $14 \cdot 6$ & 8.5 & $6 \cdot 4$ & \\
\hline 2 (safety-security) & 51 & 1.9 & $1 \cdot 1$ & $1 \cdot 8$ & $1 \cdot 2$ & $2 \cdot 6$ & \\
\hline 3 (love-belongingness) & 109 & 4.2 & 1.7 & 3.4 & 4.8 & 4.9 & \\
\hline 4 (esteem-self-esteem) & 33 & $1 \cdot 1$ & 0.6 & 0.9 & 1.5 & $1 \cdot 1$ & \\
\hline 5 (self-actualisation) & 1022 & 38.6 & $19 \cdot 8$ & 31 & $39 \cdot 8$ & $47 \cdot 6$ & \\
\hline Unable to classify & 914 & 31.5 & $43 \cdot 2$ & $16 \cdot 4$ & 12.5 & $8 \cdot 6$ & \\
\hline
\end{tabular}

BNSI, Basic Need Satisfaction Inventory.

* The percentages are weighted and therefore represent the prevalence rates as they existed in the population of Eindhoven in 2004, which is the source population. The weight factors were calculated from the distribution of the characteristics in a random sample drawn from the municipal registry in Eindhoven in October 2004.

†The numbers are unweighted and reflect the actual number of participants in the dataset.

those with no education or only primary education (23.9\%) and lowest among those with the highest education level $(8 \cdot 6 \%)$. No clear educational pattern was found among the $9 \cdot 7 \%$ of the population for whom only the first level of the hierarchy was fulfilled. Very few people were classified in the second, third and fourth layers of the pyramid, and again there was little variation according to level of education. The largest group of the population (38.6\%) indicated that all of their needs were satisfactorily fulfilled, and they consequently occupied the highest level of the pyramid. The proportion of those who were satisfied with all of their needs was highest among the highest educated (47.6\%) and lowest among the lowest educated (19.8\%). A substantial portion of the population (31.5\%) could not be classified in any layer of the hierarchy. People in this group indicated that their higher-level needs were fulfilled, but their lower-level needs were not fulfilled. The proportion of people who could not be classified in any layer of the pyramid was highest among the lowest educated (43.2\%). Participants who could not be classified were excluded from subsequent analyses.

\section{Socio-economic inequalities in food choice behaviour and the role of Maslow's hierarchy of needs}

Regression analyses showed educational inequalities for all food choice outcomes except for snack consumption (Table 2).
For bread consumption, no significant association was found in the lowest education group, even though there was an educational gradient overall in the groups. Regression coefficients indicated that a decrease in education resulted in less frequent consumption of healthy food products as compared to unhealthy food products. After adjustment for age, sex and education, the pyramid score was positively associated with fruit and vegetable consumption and more healthy than unhealthy bread consumption, snack and dairy consumption. These findings indicated that being at a higher levels in the hierarchy of needs was associated with healthier food choices. Adding the pyramid score to the model that included age, sex and education resulted in modest reductions in educational inequalities in food choice outcomes. One exception was the more substantial reduction in educational inequalities in fruit and vegetable consumption. Income equalities were found for all food choice outcomes except for snack consumption. Decreasing income resulted in fewer healthy food choices as compared to unhealthy food choices except in the case of ready meals: those in the lowest income group consumed unhealthy ready meals significantly less often as compared to healthy ready meals (Table 3). After adjustment for age, sex and income, the pyramid score was positively associated with increased fruit and vegetable consumption and more healthy than unhealthy beverage consumption. Adding the pyramid 
Table 2. Regression coefficients for educational inequalities in food outcomes and the Basic Need Satisfaction Inventory (BNSI) pyramid of the hierarchy of needs ( $B$ coefficients and $95 \%$ confidence intervals)

\begin{tabular}{|c|c|c|c|c|c|c|c|c|c|c|c|c|c|c|c|c|}
\hline & \multicolumn{4}{|c|}{$\begin{array}{l}\text { Food outcomes: } \\
\text { vegetables and fruits ( } n \text { 1988†) }\end{array}$} & \multicolumn{4}{|c|}{$\begin{array}{l}\text { More healthy than unhealthy } \\
\text { meat products }(n 1969 \dagger)\end{array}$} & \multicolumn{4}{|c|}{$\begin{array}{l}\text { More healthy than unhealthy } \\
\text { bread products }(n 1893 \dagger)\end{array}$} & & & & \\
\hline & \multicolumn{2}{|c|}{ Model $1 \neq$} & \multicolumn{2}{|c|}{ Model 2} & \multicolumn{2}{|c|}{ Model 1} & \multicolumn{2}{|r|}{ Model 2} & \multicolumn{2}{|c|}{ Model 1} & \multicolumn{2}{|c|}{ Model 2} & & & & \\
\hline & B & $95 \% \mathrm{Cl}$ & $B$ & $95 \% \mathrm{Cl}$ & $B$ & $95 \% \mathrm{Cl}$ & $B$ & $95 \% \mathrm{Cl}$ & $B$ & $95 \% \mathrm{Cl}$ & $B$ & $95 \% \mathrm{Cl}$ & & & & \\
\hline \multicolumn{17}{|l|}{ Education levelş } \\
\hline 1 (low) & $-1.79^{\star}$ & $-2.31,-1.28$ & $-1.57^{\star}$ & $-2.09,-1.05$ & $-0.65^{\star}$ & $-1.08,-0.22$ & $-0.61^{\star}$ & $-1.05,-0.17$ & -0.46 & $-0.96,0.04$ & -0.38 & $-0.88,0.13$ & & & & \\
\hline 2 & $-0.84^{\star}$ & $-1 \cdot 11,-0.57$ & $-0.70^{*}$ & $-0.98,-0.43$ & $-0.31^{*}$ & $-0.53,-0.08$ & $-0.28^{\star}$ & $-0.51,-0.05$ & $-0.33^{*}$ & $-0.59,-0.08$ & -0.28 & $-0.54,-0.02$ & & & & \\
\hline 3 & $-0.69^{\star}$ & $-0.96,-0.42$ & $-0.63^{\star}$ & $-0.89,-0.36$ & $-0.33^{\star}$ & $-0.55,-0.11$ & $-0.32^{\star}$ & $-0.55,-0.10$ & $-0.36^{*}$ & $-0.61,-0.11$ & -0.34 & $-0.59,-0.08$ & & & & \\
\hline 4 (high) & & - & & - & & - & & - & & - & & - & & & & \\
\hline \multirow[t]{2}{*}{ BNSI scale } & & & 0.15 & $0.10,0.20$ & & & 0.03 & $-0.02,0.07$ & & & 0.06 & $0.01,0.11$ & & & & \\
\hline & \multicolumn{4}{|c|}{$\begin{array}{l}\text { More healthy than } \\
\text { unhealthy beverages } \\
\qquad(n 1880 \dagger)\end{array}$} & \multicolumn{4}{|c|}{$\begin{array}{l}\text { More healthy than unhealthy } \\
\text { dairy products } \\
(n 1940+)\end{array}$} & \multicolumn{4}{|c|}{$\begin{array}{l}\text { More healthy than } \\
\text { unhealthy snacks } \\
(n 1934 \dagger)\end{array}$} & \multicolumn{4}{|c|}{$\begin{array}{l}\text { More healthy than } \\
\text { unhealthy ready meals } \\
(n 1932 \dagger)\end{array}$} \\
\hline \multirow{2}{*}{$\begin{array}{l}\text { Total sample } \\
\text { (n 2903) }\end{array}$} & \multicolumn{2}{|r|}{ Model 1} & \multicolumn{2}{|c|}{ Model 2} & \multicolumn{2}{|c|}{ Model 1} & \multicolumn{2}{|c|}{ Model 2} & \multicolumn{2}{|c|}{ Model 1} & \multicolumn{2}{|r|}{ Model 2} & \multicolumn{2}{|c|}{ Model 1} & \multicolumn{2}{|c|}{ Model 2} \\
\hline & $B$ & $95 \% \mathrm{Cl}$ & $B$ & $95 \% \mathrm{Cl}$ & $B$ & $95 \% \mathrm{Cl}$ & $B$ & $95 \% \mathrm{Cl}$ & $B$ & $95 \% \mathrm{Cl}$ & $B$ & $95 \% \mathrm{Cl}$ & $B$ & $95 \% \mathrm{Cl}$ & $B$ & $95 \% \mathrm{Cl}$ \\
\hline \multicolumn{17}{|l|}{ Education levelş } \\
\hline 1 (low) & $-0.69^{\star}$ & $-1.17,-0.21$ & $-0.65^{\star}$ & $-1.13,-0.17$ & $-1 \cdot 17^{\star}$ & $-2.05,-0.30$ & $-1 \cdot 01^{\star}$ & $-1.89,-0.13$ & 0.07 & $-0.43,0.57$ & 0.14 & $-0.37,0.65$ & -0.14 & $-0.39,0.12$ & -0.14 & $-0.40,0.11$ \\
\hline 2 & $-0.69^{\star}$ & $-0.93,-0.46$ & $-0.66^{*}$ & $-0.91,-0.42$ & -0.04 & $-0.49,0.41$ & 0.07 & $-0.38,0.53$ & 0.18 & $-0.08,0.44$ & 0.23 & $-0.03,0.49$ & $-0.31^{*}$ & $-0.44,-0.18$ & $-0.32^{\star}$ & $-0.45,-0.18$ \\
\hline 3 & $-0.32^{\star}$ & $-0.55,-0.08$ & $-0 \cdot 30^{\star}$ & $-0.54,-0.07$ & -0.02 & $-0.47,0.42$ & 0.02 & $-0.43,0.47$ & 0.05 & $-0.20,0.31$ & 0.07 & $-0.19,0.33$ & $-0.22^{*}$ & $-0.34,-0.09$ & $-0.22^{\star}$ & $-0.35,-0.09$ \\
\hline 4 (high) & & - & & & & - & & - & & - & & - & & - & & \\
\hline BNSI scale & & & 0.03 & $-0.01,0.08$ & & & $0.12^{\star}$ & $0.03,0.20$ & & & $0.05^{*}$ & $0.03,0.10$ & & & -0.040 & $-0.03,0.02$ \\
\hline
\end{tabular}

SEP, socio-economic position.

* Statistically significant $(P<0.05)$.

† Weighted sample; differences in sample size are the result of varied missing values on outcome variables.

‡ Model 1 adjusted for sex and age; model 2 additionally adjusted for BNSI scale.

$\S 1$, Low SEP (no education or primary education); 2, mid-low SEP (Iower vocational or intermediate general education); 3, mid-high SEP (intermediate vocational or higher general education); 4, high SEP (higher professional education or university). 
Table 3. Regression coefficients for income inequalities in food outcomes and the Basic Need Satisfaction Inventory (BNSI) pyramid of the hierarchy of needs (B coefficients and $95 \%$ confidence intervals)

\begin{tabular}{|c|c|c|c|c|c|c|c|c|c|c|c|c|c|c|c|c|}
\hline & \multicolumn{4}{|c|}{$\begin{array}{l}\text { Food outcomes: vegetables } \\
\text { and fruits ( } n \text { 1702†) }\end{array}$} & \multicolumn{4}{|c|}{$\begin{array}{l}\text { More healthy than } \\
\text { unhealthy meat products ( }(1686+)\end{array}$} & \multicolumn{4}{|c|}{$\begin{array}{l}\text { More healthy than } \\
\text { unhealthy bread products }(n 1621 \dagger)\end{array}$} & & & & \\
\hline & \multicolumn{2}{|c|}{ Model $1 \ddagger$} & \multicolumn{2}{|r|}{ Model 2} & \multicolumn{2}{|r|}{ Model 1} & \multicolumn{2}{|c|}{ Model 2} & \multicolumn{2}{|c|}{ Model 1} & \multicolumn{2}{|c|}{ Model 2} & & & & \\
\hline & $B$ & $95 \% \mathrm{Cl}$ & $B$ & $95 \% \mathrm{Cl}$ & $B$ & $95 \% \mathrm{Cl}$ & $B$ & $95 \% \mathrm{Cl}$ & $B$ & $95 \% \mathrm{Cl}$ & $B$ & $95 \% \mathrm{Cl}$ & & & & \\
\hline \multicolumn{17}{|l|}{ Income§ } \\
\hline $1(0-1200)$ & $-1.91^{\star}$ & $-2 \cdot 40,-1 \cdot 42$ & $-1.54^{\star}$ & $-2.05,-1.03$ & $-0.63^{\star}$ & $-1.04,-0.23$ & $-0.58^{\star}$ & $-1.00,-0.16$ & $-1 \cdot 16^{\star}$ & $-1.61,-0.71$ & $-1.07^{\star}$ & $-1.54,-0.59$ & & & & \\
\hline $2(1200-1800)$ & $-1 \cdot 28^{\star}$ & $-1.69,-0.88$ & $-1.07^{\star}$ & $-1.48,-0.65$ & -0.27 & $-0.60,0.07$ & -0.23 & $-0.57,0.11$ & $-0.40^{*}$ & $-0.77,-0.03$ & $-0.34^{\star}$ & $-0.72,-0.04$ & & & & \\
\hline $3(1800-2600)$ & $-0.77^{\star}$ & $-1 \cdot 14,-0.40$ & $-0.62^{*}$ & $-0.99,-0.25$ & $-0.33^{*}$ & $-0.63,-0.27$ & -0.31 & $-0.62,0.00$ & $-0.63^{*}$ & $-0.97,-0.29$ & $-0.59^{\star}$ & $-0.93,-0.24$ & & & & \\
\hline $4(2600-4000)$ & $-0.50^{\star}$ & $-0.84,-0.16$ & $-0.45^{\star}$ & $-0.79,-0.11$ & $-0.38^{*}$ & $-0.66,-0.10$ & $-0.37^{\star}$ & $-0.65,-0.09$ & -0.16 & $-0.47,0.15$ & -0.15 & $-0.46,0.16$ & & & & \\
\hline $5(4000+)$ & & - & & - & & - & & & & & & & & & & \\
\hline \multirow[t]{3}{*}{ BNSI scale } & & & $0.14^{*}$ & $0.08,0.20$ & & & 0.02 & $-0.03,0.07$ & & & 0.04 & $-0.02,0.09$ & & & & \\
\hline & \multicolumn{4}{|c|}{$\begin{array}{l}\text { More healthy than unhealthy } \\
\text { beverages }(n 1614 \uparrow)\end{array}$} & \multicolumn{4}{|c|}{$\begin{array}{l}\text { More healthy than unhealthy } \\
\text { dairy products }(n 1660 \dagger)\end{array}$} & \multicolumn{4}{|c|}{$\begin{array}{l}\text { More healthy than } \\
\text { unhealthy snacks ( } n \text { 1658†) }\end{array}$} & \multicolumn{4}{|c|}{$\begin{array}{l}\text { More healthy than } \\
\text { unhealthy ready meals }(n \text { 1656†) }\end{array}$} \\
\hline & \multicolumn{2}{|c|}{ Model 1} & \multicolumn{2}{|r|}{ Model 2} & \multicolumn{2}{|r|}{ Model 1} & \multicolumn{2}{|c|}{ Model 2} & \multicolumn{2}{|r|}{ Model 1} & \multicolumn{2}{|c|}{ Model 2} & \multicolumn{2}{|c|}{ Model 1} & \multicolumn{2}{|c|}{ Model 2} \\
\hline $\begin{array}{l}\text { Total sample } \\
\text { (n 2903) }\end{array}$ & $B$ & $95 \% \mathrm{Cl}$ & B & $95 \% \mathrm{Cl}$ & B & $95 \% \mathrm{Cl}$ & $B$ & $95 \% \mathrm{Cl}$ & $B$ & $95 \% \mathrm{Cl}$ & $B$ & $95 \% \mathrm{Cl}$ & B & $95 \% \mathrm{Cl}$ & $B$ & $95 \% \mathrm{Cl}$ \\
\hline \multicolumn{17}{|l|}{ Income§ } \\
\hline $1(0-1200)$ & $-1 \cdot 10^{*}$ & $-1.54,-0.65$ & $-0.95^{\star}$ & $-1.41,-0.48$ & $-1 \cdot 15^{\star}$ & $-1.97,-0.33$ & $-0.97^{\star}$ & $-1.83,-0.11$ & -0.57 & $-1.04,-0.10$ & -0.51 & $-1.00,-0.02$ & $0.27^{*}$ & $0.03,0.51$ & $0.30^{*}$ & $0.05,0.55$ \\
\hline $2(1200-1800)$ & $-0.89^{\star}$ & $-1.25,-0.53$ & $-0.80^{\star}$ & $-1.17,-0.43$ & -0.19 & $-0.86,0.49$ & -0.08 & $-0.78,0.61$ & 0.16 & $-0.22,0.55$ & 0.20 & $-0.20,0.59$ & -0.00 & $-0.20,0.20$ & 0.02 & $-0.18,0.22$ \\
\hline $3(1800-2600)$ & $-0.57^{\star}$ & $-0.89,-0.24$ & $-0.50^{*}$ & $-0.83,-0.17$ & -0.34 & $-0.96,0.28$ & -0.27 & $-0.89,0.36$ & -0.26 & $-0.62,0.09$ & -0.24 & $-0.60,0.12$ & -0.23 & $-0.41,-0.05$ & -0.22 & $-0.40,-0.03$ \\
\hline $4(2600-4000)$ & $-0.50^{\star}$ & $-0.80,-0.20$ & $-0.48^{\star}$ & $-0.78,-0.18$ & 0.13 & $-0.43,0.70$ & 0.15 & $-0.42,0.72$ & 0.06 & $-0.26,0.39$ & 0.07 & $-0.25,0.40$ & -0.16 & $-0.32,0.01$ & -0.15 & $-0.32,0.02$ \\
\hline $5(4000+)$ & & - & & - & & - & & & & - & & & & - & & \\
\hline BNSI scale & & & $0.06^{\star}$ & $0.00,0.11$ & & & 0.07 & $-0.03,0.16$ & & & 0.03 & $-0.03,0.08$ & & & 0.01 & $-0.02,0.04$ \\
\hline
\end{tabular}

* Statistically significant $(P<0.05)$

† Weighted sample; differences in sample size are the result of varied missing values on outcome variables.

¥ Model 1 adjusted for sex and age; model 2 additionally adjusted for BNSI scale.

§ Net monthly household income: 0-1200 euro, 1200-1800 euro, 1800-2600 euro, 2600-4000 euro or 4000 or more euro; those in the category 'I don't know/l don't want to provide this information' were excluded from the analysis. 
score to a model that linked income to healthy food choices again resulted in a reduction of income inequalities in fruit and vegetable consumption. For all other factors, only modest reductions in income inequalities were observed.

\section{Discussion}

\section{Summary of main findings}

In the present sample of Dutch older adults, almost $70 \%$ could be classified by Maslow's hierarchy of needs pyramid. A majority of the population had reached the level of selfactualisation, with all of their lower needs having been fulfilled. This was more often the case among more highly educated people as compared to lower educated people. The study found a higher consumption of fruits and vegetables, more healthy than unhealthy bread, more healthy than unhealthy snacks and more healthy than unhealthy dairy products with increasing levels in the hierarchy of needs pyramid. Educational inequalities in healthy food choices, however, were only marginally attenuated after the pyramid score was taken into account. Essentially similar findings were found for income inequalities in food choices.

\section{Methodological considerations}

Self-reported information about the number of days per week that respondents consumed specific food items was obtained from a FFQ. Such self-reported information is prone to reporting bias. In the present study, this is particularly relevant if the degree of bias differs by socio-economic group. Evidence suggests that higher socio-economic groups value a healthy lifestyle more than people from lower socioeconomic groups do ${ }^{(25,26)}$. This may make the former more inclined to overestimate their healthy food choices and to underestimate their unhealthy food choices. However, because lower socio-economic groups make more unhealthy food choices, the under-reporting of unhealthy food choices in lower socio-economic groups should also not be excluded. The present results are also potentially biased in cases of differential misclassification into levels of the hierarchy of needs. This would affect both the association of the hierarchy with the food choice outcomes and the contribution of needs to the inequalities in food choice outcomes. No previous study has linked Maslow's hierarchy of needs to food choice outcomes, so there is no empirical evidence for such misclassification. We believe that the added impact of such misclassification on the results would be small, because it is not immediately clear what the socially desirable answer is. Furthermore, associations between the pyramid score and food choices may be biased because of omitted confounders. For example, mental health problems may result in both ending up in a lower pyramid level and making unhealthier food choices. However, given the fact that the pyramid covers a variety of items for different domains of life, the impact of omitted confounders should not be very large.

Regression analyses excluded individuals who could not be classified in the pyramid, the majority of whom were low educated. If this group made very healthy or very unhealthy food choices, analyses would have been prone to selection bias. We therefore conducted additional analyses to assess educational inequalities in all food choice outcomes in the population, including those who could not be classified in the pyramid (data available upon request). These analyses suggested that excluding this group had a minimal impact; essentially similar educational and income inequalities in food choice outcomes were found. That a substantial part of the population could not be classified by Maslow's pyramid suggests that some participants apparently sacrificed lowerlevel needs in order to meet higher-levels needs, and this gives rise to the idea that there is no preordained order ${ }^{(27)}$. Although it deviates from Maslow's theory, we also investigated the associations between separate levels of the hierarchy and the food outcomes. After adjustment for education, age, sex and the other need levels, increased physiological need scores and increasing self-actualisation need scores were mainly related to healthier food choices. A previous study used a similar approach and found that higher self-esteem predicted less emotional eating ${ }^{(28)}$. One final methodological remark is that the present sample mainly consisted of ethnic Dutch people. This may have affected the size of the reported inequalities in health, because ethnic minorities often belong to lower socioeconomic groups and because some ethnic minorities tend to consume more fruits and vegetables than ethnic Dutch people do ${ }^{(29)}$. Therefore, we may have overestimated the socioeconomic inequalities in fruit and vegetable consumption.

\section{Comparison with other studies}

Studies that have adopted the concept of a hierarchy of needs have done so in order to develop a framework for, or to determine needs of, specific groups of patients ${ }^{(30-32)}$. Macintyre et $a l^{(33)}$ have suggested the application of the hierarchy for understanding how place characteristics may influence health.

We used the Basic Need Satisfaction Inventory developed by Leidy ${ }^{(18)}$. Although the inventory consists of twenty-seven items, additional questions related to each level would have allowed for a more precise classification. A recent study developed new (although partly overlapping) and more detailed measures of Maslow's needs based on carefully constructed operational definitions. As expected, it found that satisfaction with higherlevel needs was predicted by satisfaction with lower-level needs in a sample of American adults ${ }^{(34)}$. Education and income levels, however, did not predict self-actualisation in regression analysis. A comparison of both questionnaires would improve understanding about the impact of the operationalisation of the needs.

\section{Interpretation}

According to Maslow's hierarchy of needs pyramid, only a small part of the population should end up in the highest level of self-actualisation. In the present study of older adults in the Netherlands, however, we found that almost $40 \%$ of the study population indicated that all needs were fulfilled, including elements of self-actualisation. It is plausible that this percentage 
is lower in countries that have lower levels of welfare and in other age groups. Because wealth accumulates over people's lifetimes, it may have reached a maximum among the people in the age range studied. The discrepancy could further reflect Maslow's idea of developmental priority, according to which an individual's priorities shift from lower to higher in the hierarchy as that person ages. Lastly, it could indicate that older adults feel more satisfied with certain needs than younger people because the latter may feel that they still have not yet succeeded in life ${ }^{(35)}$.

We found that being higher in the pyramid of needs was linked to the consumption of more healthy than unhealthy food outcomes. To some extent, we also found that the fulfilment of needs was socio-economically patterned, because a larger proportion of higher-educated people reached the level of self-actualisation as opposed to lower-educated people. The present study is among the first to propose and test a mechanism that links the needs created by poor material, living, working and social circumstances to making healthy food choices. Understanding this link is important, because ignoring it may limit the effectiveness of interventions and policies.

\section{Conclusions}

In conclusion, the present study found that healthier food choices were made by people who were classified in higher levels of Maslow's pyramid of needs. Educational and income inequalities in healthy food choice behaviour, however, were only marginally explained by the pyramid score. Thus, there remains a need to better understand how the needs created by the poor material, living and social circumstances to which lower socio-economic groups are more often exposed impact food choice behaviour.

\section{Acknowledgements}

The present project was financed by a grant from the Netherlands Organisation for Health Research and Development (Healthy Food Program, project no. 115100006).

The authors' contributions are as follows: F. J. V. L. developed the concept for the study, interpreted the findings and wrote the manuscript; T. J. collected the data, analysed the data and contributed to the writing of the manuscript; C. B. M. $\mathrm{K}$. interpreted the results and contributed to the writing of the manuscript.

The authors declare no conflicts of interest.

\section{References}

1. Giskes K, Turrell G, van Lenthe FJ, et al. (2006) A multilevel study of socio-economic inequalities in food choice behaviour and dietary intake among the Dutch population: the GLOBE study. Public Health Nutr 9, 75-83.

2. Giskes K, Avendano M, BrugJ, et al. (2010) A systematic review of studies on socioeconomic inequalities in dietary intakes associated with weight gain and overweight/obesity conducted among European adults. Obes Rev 11, 413-429.

3. Pechey R, Jebb SA, Kelly MP, et al. (2013) Socioeconomic differences in purchases of more $v s$. less healthy foods and beverages: analysis of over 25,000 British households in 2010. Soc Sci Med 92, 22-26.

4. Parmenter K, Waller J \& Wardle J (2000) Demographic variation in nutrition knowledge in England. Health Educ Res 15, 163-174.

5. Ball K, Crawford D \& Mishra G (2006) Socio-economic inequalities in women's fruit and vegetable intakes: a multilevel study of individual, social and environmental mediators. Public Health Nutr 9, 623-630.

6. Le J, Dallongeville J, Wagner A, et al. (2013) Attitudes toward healthy eating: a mediator of the educational level-diet relationship. Eur J Clin Nutr 67, 808-814.

7. Black C, Moon G \& Baird J (2014) Dietary inequalities: what is the evidence for the effect of the neighbourhood food environment? Health Place 27, 229-242.

8. Bihan H, Mejean C, Castetbon K, et al. (2012) Impact of fruit and vegetable vouchers and dietary advice on fruit and vegetable intake in a low-income population. Eur J Clin Nutr 66, 369-375.

9. Magnee T, Burdorf A, Brug J, et al. (2013) Equity-specific effects of 26 Dutch obesity-related lifestyle interventions. Am J Prev Med 44, e57-e66.

10. Maslow AH (1943) A theory of human motivation. Psych Rev 50, 370-396.

11. Dunn JR (2002) Housing and inequalities in health: a study of socioeconomic dimensions of housing and self reported health from a survey of Vancouver residents. J Epidemiol Community Health 56, 671-681.

12. Bosma H, van de Mheen HD, Borsboom GJ, et al. (2001) Neighborhood socioeconomic status and all-cause mortality. Am J Epidemiol 153, 363-371.

13. Ferrie JE, Shipley MJ, Stansfeld SA, et al. (2003) Future uncertainty and socioeconomic inequalities in health: the Whitehall II study. Soc Sci Med 57, 637-646.

14. Schrijvers CT, Stronks K, van de Mheen HD, et al. (1999) Explaining educational differences in mortality: the role of behavioral and material factors. Am J Public Health 89, 535-540.

15. Powell LM, Chaloupka FJ \& Bao Y (2007) The availability of fast-food and full-service restaurants in the United States: associations with neighborhood characteristics. Am J Prev Med 33, S240-S245.

16. Thornton LE, Cameron AJ, McNaughton SA, et al. (2012) The availability of snack food displays that may trigger impulse purchases in Melbourne supermarkets. BMC Public Health 12, 194.

17. Mackenbach JP, van de Mheen H \& Stronks K (1994) A prospective cohort study investigating the explanation of socio-economic inequalities in health in The Netherlands. Soc Sci Med 38, 299-308.

18. Leidy NK (1994) Operationalizing Maslow's theory: development and testing of the basis need satisfaction inventory. Issues Ment Health Nursing 15, 277-295.

19. van Lenthe FJ, Schrijvers CT, Droomers M, et al. (2004) Investigating explanations of socio-economic inequalities in health: the Dutch GLOBE study. Eur J Public Health 14, $63-70$.

20. van Lenthe FJ, Kamphuis CB, Beenackers MA, et al. (2014) Cohort profile: understanding socioeconomic inequalities in health and health behaviours: the GLOBE study. Int $J$ Epidemiol 43, 721-730.

21. Bogers RP, Van Assema P, Kester AD, et al. (2004) Reproducibility, validity, and responsiveness to change of a short questionnaire for measuring fruit and vegetable intake. $\mathrm{Am}$ J Epidemiol 159, 900-909.

22. Drewnowski A \& Hann C (1999) Food preferences and reported frequencies of food consumption as predictors of current diet in young women. Am J Clin Nutr 70, 28-36. 
23. van Genugten L, van Empelen P, Flink I, et al. (2010) Systematic development of a self-regulation weight-management intervention for overweight adults. BMC Public Health 10, 649.

24. Baron RM \& Kenny DA (1986) The moderator-mediator variable distinction in social psychological research: conceptual, strategic, and statistical considerations. JPSP 51, 1173-1182.

25. Liberatos P, Link BG \& Kelsey JL (1988) The measurement of social class in epidemiology. Epidemiol Rev 10, 87-121.

26. Harris SM (2004) The effect of health value and ethnicity on the relationship between hardiness and health behaviors. J Pers 72, 379-412.

27. Harvath TA (2008) What if Maslow was wrong? AJN 108, 11.

28. Timmerman GM \& Acton GJ (2001) The relationship between basic need satisfaction and emotional eating. Issues Ment Health Nurs 22, 691-701.

29. Palsma AH, Nicolaou M, Van Dam RM, et al. (2006) De voeding van Turkse en Marokkaanse Nederlanders in de leeftijd van 18-30 jaar: prioriteiten voor voedingsinterventies (Food

\section{Appendix 1: Construction of outcomes based on food} items in FFQ

Participants were asked the question: How often did you consume the following products in the past month?

$$
\begin{aligned}
& (0=\text { never } \\
& 1=\text { less than } 1 \mathrm{~d} / \text { week, } \\
& 2=1-2 \mathrm{~d} / \text { week, } \\
& 3=3-4 \mathrm{~d} / \text { week, } \\
& 4=5-6 \mathrm{~d} / \text { week }, \\
& 5=\text { every day })
\end{aligned}
$$

- Vegetables and fruits: we summed scores for cooked vegetables, raw vegetables and fruits, because there are only healthy options (range: $0-15$ ).

- More healthy than unhealthy meat products: (chicken and fish/vegetarian - red meat and minced meat) (range: $-8-8$ ).

- More healthy than unhealthy bread: (whole grain bread white bread) (range: $-5-5$ ).

- More healthy than unhealthy drinks: (fruit juice - sodas) (range: $-5-5$ ).

- More healthy than unhealthy snacks (gingerbread, unsalted nuts - candy bars, chips) (range: -8-10).

- More healthy than unhealthy dairy products (skimmed milk, low-fat cheese - whole milk, fat cheese) (range: $-10-10)$.

- More healthy than unhealthy ready meals (salads, steamed ready meals - pizza, deep fried snacks) (range: -6-5).

\section{Appendix 2: The five layers of Maslow's pyramid using the Basic Need Satisfaction Inventory}

The Basic Need Satisfaction Inventory is a twenty-seven-item instrument asking subjects to rate, on a scale of 1 ('terrible') to 7 ('delighted'), how they feel about various aspects of their lives. Each item is intended to reflect one of Maslow's five basic need categories (and hence belongs to one of five conceptual subscales) intake of Turkish and Moroccan Dutch people aged 18-30 years: priorities for food intake interventions). Tijdschrift voor Gezondheidswetenschappen 84, 415-422.

30. Abraham S (2011) Fall prevention conceptual framework. Health Care Manag 30, 179-184.

31. Bayoumi M (2012) Identification of the needs of haemodialysis patients using the concept of Maslow's hierarchy of needs. J Renal Care 38, 43-49.

32. Beran D (2013) Developing a hierarchy of needs for type 1 diabetes. Diabet Med 31, 61-67.

33. Macintyre S, Ellaway A \& Cummins S (2002) Place effects on health: how can we conceptualise, operationalise and measure them? Soc Sci Med 55, 125-139.

34. Taormina RJ \& Gao JH (2013) Maslow and the motivation hierarchy: measuring satisfaction of the needs. Am J Psychol 126, 155-177.

35. Kenrick DT, Griskevicius V, Neuberg SL, et al. (2010) Renovating the pyramid of needs: contemporary extensions built upon ancient foundations. Perspect Psychol Sci 5, 292-314.

Source: Leidy ${ }^{(18)}$.

Physiological needs

Home - heat, water, lighting

Level of physical activity

Sex life

Health and physical condition

Sleep

Physical needs

Safety-security needs

Secure from stealing/destruction

Reliability of people

Safety

Secure - financially

Dependable and responsible - others

World consistent and understandable

Love-belongingness needs

Family life - wife, marriage, children

Know people - comfortable

Accepted and included by others

Close adult relatives

Friendship and love

Esteem/self-esteem needs

Respect from others

Yourself

Handle problems

Other people treat you

Self-actualisation needs

Developing self and broadening life

Enjoy pleasant/beautiful life

Creative

Fun and enjoyment

Spare time

Life as a whole 